\title{
The rise of the "service economy" in the second half of the twentieth century and its energetic contingencies
}

\section{Ulrich Witt $^{1,2} \cdot$ Christian Gross $^{3}$}

Published online: 27 November 2019

(C) The Author(s) 2019

\begin{abstract}
The characteristic of the "service economy" is the rise to dominance of the service sector in terms of employment and value added shares. We track this rise during the second half of the twentieth century for the U.S., more precisely the period from 1970 to 2005. Following seminal work by Baumol (1967) the rise is often attributed to growing productivity differentials between the economic sectors. The causes of the productivity differentials are, however, controversial. Inspired by Georgescu-Roegen's (1971) evolutionary approach to production theory, the present paper explores whether differences in the energetic features of the sectors' production technologies contribute to the growing sectorial productivity differentials. For the data for our period of analysis it turns out that a close relationship indeed exists between the sectors' incentives for substituting relatively cheap energy for ever more expensive labor and their labor productivity gains. In highly energy-dependent sectors an increasing energy/labor ratio has been driving productivity growth while this was not the case in the service sector. The paper closes with a short discussion of what the finding may imply for the future of the service economy.
\end{abstract}

Keywords Service economy · Sectorial change · Productivity growth · Energy · Employment

JEL classification D24 $\cdot$ E23 $\cdot \mathrm{O} 14 \cdot \mathrm{Q} 43$

Ulrich Witt

ulrich.witt@evoecon.mpg.de

1 Max Planck Institute for Science of Human History, Jena, Germany

2 Griffith Business School, Griffith University, Gold Coast, QL, Australia

3 Ministry of Justice \& Consumer Protection, Berlin, Germany 


\section{Introduction}

Structural change in the economy is an inevitable concomitant of economic growth. Its impact is visible, not least, in the shifting employment and value added shares of the different sectors of the economy. In the early phases of economic growth, the expansion of the industrial sector dominates (at the expense of an agricultural sector shrinking to minor significance). But its dominance is soon contested by the service sector. In fact, by the end of the twentieth century, there is no advanced economy in which the service sector has not absorbed the largest share of employment and value added (see, e.g., Schettkat 2007). This transformation - often described as the rise of the "service economy" - has since long been noted and addressed in economics (see, e.g., Fourastié 1952, Chenery 1960, Kuznets 1971, Pasinetti 1993). Nonetheless, the causes and contingencies are still not entirely clear.

An explanation that is frequently cited goes back to Baumol (1967) who identified a "cost disease" in the service sector and attributed it to a lower productivity growth in that sectors. In a nutshell he argued as follows (see, e.g., Nordhaus 2008). Let the productivity of labor in the industrial sector increase faster than in the service sector. Wages in the industrial sector are then likely to rise. If the labor market is sufficiently competitive to prevent the wage levels in the two sectors from drifting apart, labor costs per unit of output in the service sector increase relative to those in the industrial sector. As a consequence, the price level of services increases relative to that of industrial products. Provided the rising prices of services do not induce a strong substitution of industrial products for services, the paradoxical result is that the sector with the lower productivity gains grows more in terms of the value added than the sector with the higher productivity increases. At the same time, relatively more jobs are maintained or generated (as a result of economic growth) in producing services rather than in industrial production so that the employment share of the service sector also goes up.

This explanation is supported by several empirical observations (Baumol et al. 1985). Productivity differentials between the sectors and corresponding wage cost differentials per unit of output indeed grew over time. Despite a significant increase of the relative price level of services, a large-scale substitution of services by industrial products did not take place. Under these conditions it is not surprising that the employment share of the service sector grew. Because of the inflated relative prices of services the value added share of the service economy must also grow (Henriques and Kander 2010, Baily and Bosworth 2014). The question left open is why there are productivity differentials between the sectors in the first place.

To explain the differentials one can refer to the sectors' strongly differing capital intensity which is ultimately a consequence of the sectors' production technology. Industrial production involves the transformation and relocation of materials to a large extent at a mass production scale. This requires relatively more machinery and other equipment per unit of output than the production of services. However, the sectors' differing capital requirements are intimately connected to another feature of their production technologies by which they differ a lot, namely their energetic requirements. As convincingly argued by Georgescu-Roegen (1971) with reference to the second law of entropy, an exclusive focus on capital would ignore that industrial production processes are fundamentally dependent on the use of relatively cheap, nonanthropogenic energy. For most of the production taking place in the service sector 
this is not true, a fact reflected in the significant difference of the sectors' energy/output ratios. The question thus arises what role the energetic differences between the sectors' production technologies play for the inter-sectorial productivity differentials and, hence, for the rise of the service economy.

The present paper is devoted to a discussion of this question. Focus is on a period in the twentieth century during which the service sector in the U.S. gained its present dominance over the other sectors of the economy. Following Georgescu-Roegen's plea that physical features and energetic constraints matter for understanding economic production processes we explore the energetic contingencies of this rise to dominance. In Section 2 we discuss the energetic differences between the sectors' production technologies. They result in unequal incentives for the sectors to take advantage of the era of relatively cheap energy through substituting energy for increasingly more costly labor inputs. With these considerations in mind we briefly review in Section 3 the empirics of the rise of the service economy in the U.S. in the years from 1970 to 2005. During this period there were no significant policy interventions yet, addressing the climate change effects of national energy consumption. Moreover, the U.S. economy experienced a comparatively stable phase of growth. These conditions only changed substantially with the Kyoto climate protection protocol entering into force in 2005 - leading to a first commitment period 2008-2012 - and the financial crisis in 2008, respectively (both likely to disrupt the circumstances under which sectorial change had taken place before).

In Section 4 we introduce a simple sectorial production function model. It serves to specify a testable hypothesis, namely that during the period 19702005 the sectors' unequal energetic substitution incentives correspond to differences in the extent to which productivity changes can be attributed to a changing energy/labor ratio. In Section 5 we describe the data and the method we use to test the hypothesis. Section 6 summarizes the test results and discusses some insights that may be drawn from the analysis regarding the future of the service economy. Section 7 presents the conclusions.

\section{The role of energy in the sectors' production technology}

Economic growth is associated similarly in all advanced economies with a systematic shift of value added and employment from industry to services. In their seminal attempt to explain the persistent phenomenon Baumol and Bowen (1966) argued that labor productivity in the industrial sector increases more rapidly than in the service sector. Following the productivity increases wages in the industrial sector increase. But with a competitive national labor market, wages in the service sector rise similarly despite the lower productivity increases in that sector. The result is a "cost disease" in the service sector (as Baumol and Bowen put it) pushing up the relative price of services. If the price change is not completely compensated by a substantial substitution away from services, the value added and employment shares of the service sector must grow.

This explanation of sectorial change and the rise of the service economy leaves open what causes the sector's productivity differentials in the first place. Several developments can be conjectured to play a role here, technological ones and organizational ones. Regarding organizational changes, an important example is the off-shoring of the labor- 
intensive parts of manufacturing processes of the industrial sector to low-wage countries (see Houseman et al. 2011). Another example is the off-shoring of industrial production activities in an attempt to evade tightening environmental and other regulations in the highly developed economies (see Kellenberg 2009). Off-shoring of labor-intensive production affects the employment share of the industrial sector negatively, but raises labor productivity in the remaining domestic industry. Off-shoring of polluting and other regulated activities seems to affect only few industries and without a systematic effect on their labor productivity (Walker 2013; Dechezlepretre and Sato 2017). ${ }^{1}$

However, massive cross-border relocation of production activities is a relatively recent phenomenon. It is associated, in particular, with the economic globalization process after the Cold War ended in the 1990s and extended free-trade policies that encouraged the exploitation of international wage differentials and/or differences in taxation and regulatory regimes. For the divergence of the domestic sectorial productivity trends that took place already long before, organizational adaptations seem less significant than technological developments. Among them, the capital intensity of the sectors - high in industrial production and low in service production - is commonly assumed to be responsible for the productivity differentials. However, differences in the capital intensity no less require an explanation. To provide one we suggest following Georgescu-Roegen's (1971) evolutionary approach that highlights the physical properties of the respective production processes.

Industrial production is largely mass production in which materials are transformed in one way or other. By standardizing the transformation processes they can be transferred to properly constructed machinery, automatized, and replicated in parallel, i.e. fast and in very large numbers - if the necessary investments into capital stock take place. However, ingenious as the engineering of the productivity enhancing, capitalbased mass production is, from a physical point of view the capital stock does not do any work, i.e. transform materials, unless it is powered by utilizable energy ("exergy"). Put differently, capital mediates the generation/extraction, transmission, and application at the point of use of energy that actually effects the material transformations. ${ }^{2}$

In the spirit of Georgescu-Roegen's approach, industrialization can thus be understood as a large scale implementation of an "industrial metabolism" (Ayres and Simonis 1994). It is driven by non-anthropogenic, mostly fossil, energy which is mediated by a growing capital stock. Per unit of the growing output less and less human labor is needed. Yet, because of the unprecedented growth of output, employment of labor in the industrial production process remains high, now increasingly in the form of engineering, controlling, managing, maintenance, repair, and administrative activities. Labor productivity rises as does a new variable that is crucial for the industrial sector: the ratio between non-anthropogenic energy and labor inputs (measured in time units).

\footnotetext{
${ }^{1}$ Still other forms of organizational change modify the sectors' vertical integration. Labor intensive service activities such as engineering, design, marketing, finance, ICT consulting, or legal services previously carried out within industrial firms may, for example, be outsourced to independent firms which, in terms of the sectoral statistics, count as part of the service sector. The effect in national accounting is a transfer of employment and value added from the industrial sector to the service sector, see Fixler and Siegel (1999).

2 See Buenstorf (2004) Chap. 4 and Chap 2 for an explication of the notion of "exergy" or utilizable energy. In pre-industrial times, in contrast, materials were transformed by small scale handcraft production. The technology was based on the application of human physical work aided by animal, wind, and water power. Accordingly, comparatively little capital was needed for generating and applying that kind of energy.
} 
In physical terms, the production technology of the service sector is obviously a different one, particularly if transport services are considered separately from the rest of the service sector. ${ }^{3}$ Unlike in the industrial sector, the transformation of materials is limited to handicraft works such as in maintenance and repair services and, thus, of minor importance. Exclusive of transport services, the bulk of the productive activities consist of providing caring and hospitality services, creative works, administrative, trading and informationrelated services of all sorts. In producing these services, energy obviously plays only a minor role (except in only most recently created information services related to the internet and cloud storing). Accordingly, the sector can be expected to also need less capital but significantly more labor for its production. More specifically this means that more labor is used per unit of output the inverse of labor productivity - which also implies a lower energy/labor ratio than in the industrial sector.

The differences between the sectors' physical production conditions, particularly their significantly differing energy-dependency and labor intensity, translate into different sectorial cost structures. Moreover, the sectors' cost structures expose them differently to changing input prices. During the second half of the twentieth century - the time of the ascendancy of the service economy in all advanced economies - wage costs increased substantially in the advanced economies relative to the price of energy (Ayres and Warr 2009). The relative input price changes can be conjectured to have induced a substantial incentive to substitute energy (and capital mediating its use) for labor where production activities are relatively energy intensive and where, therefore, taking advantage of the falling energy price was worthwhile to do. Such production activities are characteristic of the industrial sector and the transport sector, but not in service production. If our conjecture is correct, the rising energy/labor ratio in the first two sectors can be expected to have the paradoxical effect of boosting the employment share and the value added share of the c\&c service sector where energy is technologically least important.

\section{A case in point: Sectorial change in the U.S. economy 1970 to 2005}

In order to assess the empirical validity of the hypothesis that energetic factors have contributed in the outlined way to the ascendency of the service economy in the second half of the twentieth century we use data for the U.S. covering the years 1970 to 2005 . We choose this period because it represents an episode particularly well suited for a test. As a result of the two OPEC oil crises in the 1970s, policy making became increasingly aware of the critical role which the availability of cheap fossil energy played in backing economic growth. Ensuring a steady supply of cheap energy was high on the political agenda while concerns relating to the climate change effects of fossil energy consumption did not yet result in significant political activity or even a paradigmatic change in energy policy. Furthermore, during the period of our analysis the economy was not yet heavily

\footnotetext{
3 Transport services mainly consist of carrying out physical work, namely moving freight and/or passengers together with the vehicles carrying them from one location to another.
} 
affected by the disruptive innovations of the digital information revolution, the internetbased dot-com economy, and major financial turmoil as it culminated in the crisis of 2008.

As already mentioned, in the national sectorial classification, the service sector comprises of productive activities that are very heterogeneous particularly with respect to their dependence on energy as a production factor. To account for at least the most significant differences in this respect we separate in our analysis the extremely energyintensive transport services from all other services which we label commercial \& consumer services (c\&c services). Thus we track the record of sectorial change in the U.S. on the basis of three aggregate sectors: industry, transport, and c\&c services. ${ }^{4}$

The dominance of the c\&c service sector is already apparent in the U.S. in 1970, reflected by its employment share of $61 \%$. But in 2005 the share has risen even further to $76 \%$. For a summary statistic of the shares of all three sectors see line 1 in Table $1 .^{5}$ Similarly, the value added share of the c\&c service sector - deflated over the observation period in terms of the GDP price index - grows from $63 \%$ to $76 \%$ (line 2 in Table 1). Its increase turns out to be substantially smaller, however, if sectorial rather than macro price levels are used for the correcting price inflation. Because of the relatively more strongly rising price level for services the value added share of the sector then grows from $63 \%$ to only $66 \%$. Correspondingly, the industry's decline in value added adjusted for sectorial price inflation difference appears much less dramatic (see lines 2 and 3 in Table 1).

This observation accords with Baumol's cost disease diagnosis. As he assumed, the wage level increased substantially and similarly across the sectors except for transport falling slightly behind (see line 4 in Table 1). Accordingly, when calculated on the basis of the GDP price index, labor productivity increases from 1970 to 2005 were not much different between the sectors (line 5 in Table 1). When, however, the changes in relative prices between the sectors are singled out by using a sector-specific deflator, the significantly lower productivity increase in the c\&c service sector becomes visible. While labor productivity grew by the factor 3.1 in the industrial sector, and by the factor 2.5 in transport, the increase in the production of services was only one by factor 1.7 (line 6 in Table 1). Put differently, the prices of c\&c services rose to an extent that did not only overstate the sector's value added share in GDP, but also compensated for the actual productivity differentials between the sectors (Henriques and Kander 2010).

The energetic differences between the sectors' production technologies are reflected by the fact that in 2005 the industrial sector produced one unit of output with almost seven times the energy required per unit of output in the service sector. In the transport sector it was even a remarkable 23 times the energy (line 7 in Table 1). The huge differences reflect the energy-intensity of the industrial transformation processes and of the work done for relocating objects. For mediating the application of energy in its production, the industrial

\footnotetext{
${ }^{4}$ The sector c\&c services includes wholesale trade, retail trade, information, finance, insurance, real estate, rental and leasing, professional and business services, educational services, health care and social assistance, arts, entertainment, recreation, accommodation and food services, and government. In terms of the amount and technical conditions of energy utilization, c\&c services are still a fairly heterogeneous conglomerate. Nonetheless, the variation within this sector is smaller than that between c\&c services and transport (comprising of transportation and warehousing; we exclude the largely non-commercial transportation related to the residential sector). Since the primary sector, i.e. agriculture, forestry, fisheries, etc., is in advanced economies of minor importance for sectoral change it has been omitted from our analysis. The percentage shares which are given for the three sectors therefore add up to $100 \%$.

5 The data we use in this section for descriptive purposes and their sources are explained in detail in Section 5.
} 
Table 1 U.S. Sector Statistics for 1970 and 2005

\begin{tabular}{llll}
\hline Sector & Industry & C\&C Services & Transport \\
\hline (1) Employment share in \% & $21(35)$ & $76(61)$ & $3(4)$ \\
(2) Value added share in \% (macro deflator) & $21(33)$ & $76(63)$ & $3(4)$ \\
(3) Value added share in \% (sector deflator) & $30(33)$ & $66(63)$ & $4(4)$ \\
(4) $\Delta$ Wage level relative to c\&c service sector & 1.0 & 1.0 & 0.8 \\
(5) $\Delta$ Labor productivity (macro deflator) & 1.9 & 1.7 & 1.7 \\
(6) $\Delta$ Labor productivity (sector deflator) & 3.1 & 1.7 & 2.5 \\
(7) Energy/Output ratio & $12.9(22)$ & $1.9(3.2)$ & $44.1(43.5)$ \\
(8) Energy/Labor ratio & 0.56 & 0.01 & 1.15 \\
(9) $\Delta$ Energy/Labor ratio & 1.1 & 1.0 & 1.7 \\
(10) Energy/Capital ratio & 20.0 & 5.26 & 12.5 \\
(11) $\Delta$ Energy/Capital ratio & 0.53 & 0.45 & 0.77 \\
\hline
\end{tabular}

Note: Values for 1970 in brackets; $\Delta$ denotes the growth factor $(1970=1)$. Source: see Section 5

sector needed almost twice (the transport sector ten times) as much capital per unit of output as the c\&c service sector (calculated from lines 7 and 10 in Table 1). The labor-intensive production in the service sector shows up in the labor/output ratio which is five times the size of that ratio in the industrial sector and twice the size of the ratio in in the transport sector (calculated from lines 7 and 8 in Table 1). The energy/labor ratio in the industrial sector (in the transport sector) is 56 times (115 times) as large as that of the service sector (line 8 in Table 1).

A good indicator for the energy price increases from 1970 to 2005 is the rising price of oil. After decades with extremely low, stationary oil prices, the sudden price increases in the 1970s were experienced as a crisis (see Berndt and Wood 1975). Yet, once set in motion, the price hikes continued with major fluctuations throughout the entire period. However, wage increases were even higher. ${ }^{6}$ The diverging development of the relative input prices kept a substitution incentive alive albeit, for reasons of their production technologies, the incentive differed between the sectors. In the c\&c service sector where energy plays a minor role in production - indicated by a very low energy/ labor ratio - there is no great potential for saving by substitution. In industry and transport, in contrast, the technical conditions allowed to a much larger extent to take advantage of relatively cheaper energy.

Considering these differences we suggest:

\section{Hypothesis 1}

\footnotetext{
${ }^{6}$ Take, for example, average hourly earnings of production and nonsupervisory employees in the U.S. in current U.S. \$ (U.S. Bureau of Labor Statistics, retrieved from https://fred.stlouisfed.org/series/AHETPI) as indicator of the relevant wages and the average annual OPEC crude oil price in current U.S. \$ retrieved from https://www.statista.com/statistics/change-in-open-crude-oil-prices-since-1960/ as indicator for the price of energy. The change of the relative input prices can then be represented by wages growing by roughly $60 \%$ more between 1970 and 2005 than energy prices (based on a linear trend fitted to the strongly fluctuating crude oil price 1970-2005).
} 
During the period 1970 - 2005 the substitution of cheap energy for labor in industry and transport - associated with energy/labor ratios increasing from the already very high levels (line 9 in Table 1) - contributed to the rising labor productivity in these sectors. This was not the case in the $c \& c$ service sector.

The differences between the sectors regarding the relationships between labor productivity (the key variable in Baumol's explanation of sectorial change) and the energy/ labor ratio (affected by the substitution process) can be explicated more precisely by means of a simple sectorial production function model.

\section{The energy-dependency of the sectorial productivity differentials}

In the previous section we have argued that differing physical, particularly energetic, production conditions of the economic sectors contributed to the sectorial change in the U.S. characterized by a further rise of the service economy. The discussion of the differences and their effects led to the formulation of Hypothesis 1 . In this section, we introduce a simple sectorial production function model. By way of a counterfactual argumentation it can serve to derive a null hypothesis required for an empirical test of Hypothesis 1 .

Let the sectors of the economy be denoted by the suffix $i$ and time by the suffix $t$. Let $E_{i t}$ denote the (non-anthropogenic) energy consumed in production and $K_{i t}$ the capital stock installed at time $t$. A certain fraction of the installed capital stock may be idle, e.g. because of lack of orders. We therefore denote the fraction actually operated in production by $u_{i t} K_{i t}, 0<u_{i t} \leq 1$. Thus, $u_{i t}$ can be interpreted as a measure of capacity utilization.

The technology embodied by the capital vintages installed at time $t$ implies an energetic constraint. To produce a certain amount of output, a minimal amount of energy (determined by the technical efficiency bound of the equipment) is required for operating the active fraction of the capital stock. Assuming a technically efficient production, the energy/capital ratio $\varepsilon_{i t}>0$ is a technological parameter of the capital vintages installed at time $t$ that determines the energy consumption of the active fraction of capital, ${ }^{7}$

$$
E_{i t}=\varepsilon_{i t} u_{i t} K_{i t}
$$

Suppose - contrary to Hypothesis 1 (and the factual situation) - all three sectors would share the same technology. The substitution elasticity of labor for capital (or, because of Eq. (1), for energy) could then be assumed to be the same in all sectors. Setting it for expository convenience equal to one, the production conditions could be approximated in all sectors alike by a simple Cobb-Douglas production function of the form

\footnotetext{
${ }^{7}$ While $u_{i t}$ fluctuates without any trend during the period 1970-2005 in the U.S., line 11 in Table 1 shows that the energy efficiency of the capital stock and, hence, $\varepsilon_{i t}$ decreased in all three sectors. As a result of the first oil crisis in the 1970s, empirical explorations of the relationships between energy and capital gained momentum. Within the industrial sector the relationship has been found to mostly be one that is near to complementarity (as assumed in Eq. (1)), see, e.g., Kim and Heo (2013), Costantini and Paglialunga (2014), Fiorito and van den Bergh (2016).
} 


$$
Y_{i t}=A_{i t}\left(K_{i t}\right)^{\alpha_{i}}\left(L_{i t}\right)^{1-\alpha_{i}},
$$

where $Y_{i t}$ denotes value added, ${ }^{8} A_{i t}$ denotes the unexplained total factor productivity (TFP), and $L_{i t}$ denotes labor input. On that basis of Eq. (2) a null hypothesis for testing Hypothesis 1 will be formulated in the next section. Before, however, some qualifications regarding the factor labor and the total factor productivity (TFP) term in the equation are in order.

In a period extended over several decades, technical progress improves the energy efficiency of the capital stock as a concomitant of the changing capital vintages in operation. We account for this development by allowing the parameter $\varepsilon_{i t}$ to vary over time. However, human capital and, hence, the quality of labor services is likely to improve as well over time. An important part of the improvements is due to extended training that contributes to up-skilling and labor productivity increases (see Buera and Kaboski 2012). To account for this development we treat the labor input $L_{i t}$ required in $t$ for enabling the production of a sector's output $Y_{i t}$ as the sum of (usually unpaid) labor skilling time $L_{i t}^{S}$ and paid labor $L_{i t}^{P}$ (measured in hours of contracted working time). Writing $L_{i t}^{S} / L_{i t}^{P}=\sigma_{i t}>0$, this amounts to

$$
L_{i t}=\left(1+\sigma_{i t}\right) L_{i t}^{P} .
$$

Inserting Eqs. (1) and (3) into (2) we get

$$
Y_{i t}=\widetilde{A}_{i t}\left(E_{i t}\right)^{\alpha_{i}}\left(L_{i t}^{P}\right)^{1-\alpha_{i}}
$$

as transformed production function. In Eq. (4) the ongoing augmentation of production is captured by the variable

$$
\widetilde{A}_{i t}=A_{i t}\left(\frac{1}{\varepsilon_{i t} u_{i t}}\right)^{\alpha_{i}}\left(1+\sigma_{i t}\right)^{1-\alpha_{i}}
$$

as the weighted product of unexplained TFP (representing overall technical progress), improved energy efficiency of the employed capital stock, and improved human capital inputs due to upskilling.

The desired relationship between the energy/labor ratio as independent variable and labor productivity as dependent variable results by dividing Eq. (4) by $L_{i t}^{P}$. By taking $\operatorname{logs}$ the sectors' labor productivity can then be written as a function of the energy/labor ratio in the form

$$
y_{i t}=a_{i}+\alpha_{i} b_{i t}+\left(1-\alpha_{i}\right) c_{i t}+\alpha_{i} d_{i t},
$$

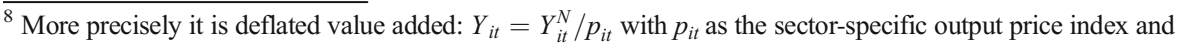
$Y_{i t}^{N}$ as nominal value added measured in current US-\$.
} 
where $y_{i t}=\ln \left(\frac{Y_{i t}}{L_{i t}^{P}}\right)$ denotes the log of labor productivity, $a_{i}=\ln A_{i t}$ denotes the log of unexplained TFP, $b_{i t}=\ln \left(\frac{1}{\varepsilon_{i t} t_{i t}}\right)$ denotes the $\log$ of the term reflecting the energy efficiency of capital, $c_{i t}=\ln \left(1+\sigma_{i t}\right)$ denotes the log of the labor-skilling factor, and $d_{i t}$ $=\ln \left(\frac{E_{i t}}{L_{i t}^{P}}\right)$ denotes the log of energy/labor ratio.

\section{Data and test methodology}

The data we use for the empirical test cover the period 1970 to 2005 and are compiled as follows. Those for GDP and value added in the sectors industry, c\&c services, and transport are taken from the statistics published by the U.S. Bureau of Economic Analysis (2010). The data are composed according to the North American Industry Classification System (NAICS). To transform the output measures into constant U.S. Dollars, we use sector specific deflators for sectorial value added as well as a GDP deflator for total GDP. The deflators are provided by the same source.

Energy data are provided by the Energy Information Administration (2011a, b, c, d). They cover the same sectors as the output data do. The energy input is measured as final energy consumption in Billion British thermal units (Btu). The data on hours of work are taken from the EU-KLEMS Growth and Productivity Accounts (2009a, b), as are those for the capital stock which are used for calculating the capital-energy ratio The value of the capital stock is calculated in constant U.S. Dollars. For the calculation of the capitalenergy ratio in the c\&c service sector we exclude real estate. Data on capacity utilization in the industrial sector are provided by the Federal Reserve Board (2011). For the other two sectors we use the employment rate (i.e. one minus the unemployment rate as given by the Bureau of Labor Statistics 2011) as a proxy for capital utilization. The up-skilling factor for human capital is approximated by years of schooling taken from the UNESCO Institute for Statistics database (2011). All variables have been transformed to logs.

In view of the rather small sample size available to us we resort to a cointegration test for examining the empirical validity of the claim. If the time series of each sector enter a cointegration relationship, this means that the variables share a common stochastic trend. More precisely, our null hypothesis therefore is that labor productivity as the dependent variable varies in a stable, co-integrated way with the independent variables, in particular the energy-labor ratio, in each of the three sectors.

For the test we apply the ARDL bounds testing procedure developed by Pesaran and Shin (1999) and Pesaran et al. (2001). Compared to other approaches such as those suggested by Engle and Granger (1987) and Johansen and Juselius (1990) the ARDL approach has several advantages. First, it does not require examining the nonstationarity property and order of integration of the variables. Second, bounds tests allow to derive robust results for small sample sizes like the present one (Pesaran and Shin, 1999). Third, in empirical studies, energy market-related variables have proven to almost always be integrated of order $1[I(1)]$ or of order $0[I(0)]$ (Narayan and Smyth, 2007, 2008), justifying the application of ARDL for our analysis. Narayan (2005) provided tables with critical F-values for sample sizes ranging from 30 to 80. As our sample size is within this range, we use the critical values provided by Narayan. 
The ARDL bounds testing procedure involves two steps: (i) we use the semiparametric test by Phillips and Perron (1988) to ensure that the variables are not integrated of order 2 [I (2)]; (ii) we apply an unrestricted error correction model (ECM) to test for cointegration among the variables and display also the short-run dynamics. ${ }^{9}$ The regression equation can be derived from Eq. (6). Accordingly, the notation of an unrestricted $\mathrm{ECM}$ in first log-differences for the $\operatorname{ARDL}\left(p, q_{1}, q_{2}, q_{3}, q_{4}\right)$ bounds test is

$$
\begin{aligned}
\Delta y_{i t}= & a_{i}+\beta_{i 1} y_{i t-1}+\beta_{i 2} b_{i t-1}+\beta_{i 3} c_{i t-1}+\beta_{i 4} d_{i t-1}+\sum_{j=1}^{p-1} \theta_{i j 1} \Delta y_{i t-j} \\
& +\sum_{j=0}^{q_{1}-1} \theta_{i j 2} \Delta b_{i t-j}+\sum_{j=0}^{q_{2}-1} \theta_{i j 3} \Delta c_{i t-j}+\sum_{j=0}^{q_{3}-1} \theta_{i j 4} \Delta d_{i t-j}+\eta_{i t},
\end{aligned}
$$

where the suffix $i$ indicates either one of the sectors industry, c\&c services, and transport or the national (macro) level. The residual term $\eta_{i t}$ is assumed to be a white noise error process. The lag length of the explanatory variables is denoted by $q$. The optimal lag order is selected following the minimum values of the Bayesian information criterion (BIC). According to Pesaran et al. (2001), the BIC is generally a preferred choice, because it tends to define more parsimonious specifications. The 'no cointegration' condition is tested by means of an F-test of the joint significance of the lagged level coefficients: $H_{0}: \beta_{i 1}=$ $\beta_{i 2}=\beta_{i 3}=\beta_{i 4}=0$. The null hypothesis of no cointegration is to be rejected if the upper critical bound is less than the computed F-statistic.

\section{Empirical results and policy implications}

The results of the stationarity tests (see Table 2) show that all of the variables are nonstationary at level. After differencing the variables once, all variables are confirmed to be stationary. As none of the variables is integrated of order two, the ARDL bounds procedure can be used to examine the existence of a cointegration relationship among the variables.

The results of the ARDL bounds test are given in Table 3. For the industrial sector and the transport sector the F-statistics exceed the critical F-values provided by Narayan (2005). ${ }^{10}$ It can therefore be inferred that, in these two sectors, labor productivity varies in a stable, co-integrated way with the explanatory variables, particularly the energy-labor ratio. Moreover, the fit of the model and the values of the constant representing the unexplained technological progress, which are found to be low (transport) or insignificant (industry), indicate that the development of labor productivity is well described by the selected explanatory variables.

In contrast, no stable co-integrated relationship is found for the $\mathrm{c} \& \mathrm{c}$ services sector. Hence, our null hypothesis that labor productivity varies in a stable, co-integrated way

\footnotetext{
${ }^{9}$ The ARDL modeling approach does not require unit root tests to check whether all variables are $I(0)$ or $I(1)$. Nonetheless, we conduct the unit root test to ensure that no variable is $I(2)$ or higher. If a variable were found to be $I$ (2), the critical F-statistics computed by Pesaran et al. (2001) and Narayan (2005) would no longer be valid.

${ }^{10}$ The critical values for the investigation of the long-run relationship are 6.988, 5.090, 4.274 at the $1 \%, 5 \%$, 10\% level of significance (case IV, p. 1989 in Narayan, 2005).
} 
with energy-labor ratio, in each of the three sectors can be rejected. The result of the test supports Hypothesis 1. Labor productivity in the c\&c service sector is not in the same way affected by changes in the energy/labor ratio and, hence, by substitution incentives due to cheap energy. A replacement of cheap energy for ever more expensive labor as suggested by Eq. (6) explains productivity increases only where energy is essential for production, i.e. in the industrial sector and in transport. At the macro level, the different, energy-related responses of the sectors are not visible, because total GDP is dominated by the inflated value added of the c\&c service sector (see Gross 2012 for a discussion).

What insights does our analysis of the rise of the service economy possibly suggest for an era in which, due to the climate change problem, the saving of fossil energy consumption has won a high priority for policy makers? It seems that in a period during which policy making (at least in the U.S.) focused on ensuring a steady fossil energy supply rather than on raising energy efficiency, relatively cheap energy could play out its cost advantage selectively in industry and transport. The c\&c service sector did not benefit to the same extent. Paradoxically, this sector therefore increased its value added and employment share. This energetic contingency of the rise of the service sector is largely ignored when it is sometimes argued now that a further growth of the service sector could help pushing the de-carbonization of the economy.

There is broad agreement that the de-carbonization of the economy is of utmost importance for coping with the climate change problem. But the pursuit of this goal may impede the further rise of the service sector rather than being pushed by it. There may be a policy dilemma implied, if a continued relative growth of the $\mathrm{c} \& \mathrm{c}$ service sector is also considered desirable (as it may be from the point of view of moderating the ongoing structural change of the economy). If the energetic contingencies which we identified for the past continue to prevail, the two desiderata can both be realized only, if one of two conditions (or both) are met. One condition is that the new energy sources replacing fossil energy also allow the energy price/wage ratio to fall. The other condition is that the energy efficiency of industrial processes and transport is vastly increased - notwithstanding the physical limits to raising the efficiency of energy conversion processes. (In Eq. (6) of our model the latter condition amounts to a decreasing parameter $\varepsilon_{i t}$ with a positive effect on labor productivity at any level of the energy/labor ratio.)

What the chances for satisfying these conditions there are is not evident. However, policy making can contribute to improving the chances. One option would be to heavily subsidize the costs of generating non-fossil energy, trusting that this measure can bring about a falling energy price/wage ratio. Another option would be the promotion of research into, and technical development of, techniques and devices that enhance energy efficiency. One can think here of public procurement of significantly energy-improved prototypes (where possible), of substantially up-scaled subsidies for private R\&D on energy efficiency, and/or of prioritizing corresponding publicly funded research.

The relevance of consideration like these depends, of course, on whether the energetic contingencies of sectorial change for which we found evidence in the second half of the twentieth century remain robust also for the time to come. In view of the deep-going disruptions caused by the digital information revolution (not to speak of the financial crisis in 2008) and the paradigmatic change in the climate protection policies that have occurred since, this is uncertain. We will be able to find out - once over a sufficiently long observation period the overall economic conditions have been stabilized again and the economy has adjusted to the new policy paradigm. 
Table 2 Results of the Phillips-Perron Test

\begin{tabular}{|c|c|c|c|}
\hline Sector & Variable & Level & First difference \\
\hline \multirow[t]{4}{*}{ Macro } & $\mathrm{y}$ & -0.275 & $-4.560^{* * *}$ \\
\hline & $\mathrm{b}$ & 0.08 & $-4.219^{* * *}$ \\
\hline & $\mathrm{c}$ & -1.77 & $-8.175^{* * *}$ \\
\hline & $\mathrm{d}$ & -1.27 & $-4.073 * * *$ \\
\hline \multirow[t]{3}{*}{ Industry } & $\mathrm{y}$ & 1.831 & $-5.469 * * *$ \\
\hline & $\mathrm{b}$ & -1.388 & $-3.289^{* * *}$ \\
\hline & $\mathrm{d}$ & -1.245 & $-3.601 * * *$ \\
\hline \multirow[t]{3}{*}{ c\&c Services } & $\mathrm{y}$ & -0.544 & $-5.308^{* * * *}$ \\
\hline & $\mathrm{b}$ & 1.223 & $-5.442 * * *$ \\
\hline & $\mathrm{d}$ & -1.624 & $-5.439 * * *$ \\
\hline \multirow[t]{3}{*}{ Transport } & $\mathrm{y}$ & -0.04 & $-5.882 * * *$ \\
\hline & $\mathrm{b}$ & 0.221 & $-3.325 * * *$ \\
\hline & $\mathrm{d}$ & -2.546 & $-4.994 * * *$ \\
\hline
\end{tabular}

Note: ***, **, * denotes $1 \%, 5 \%, 10 \%$ level of significance, respectively

\section{Conclusions}

This paper explored the role that energy plays in the context of the growth of the service economy. The inspiration for taking an energetic perspective is Georgescu-Roegen's evolutionary approach to economics in which energy is a key factor for understanding how output is produced. Empirical tests of the statistical relationship between energy utilization and economic performance usually focus on the effects on aggregate output and frequently reject the hypothesis that energy has a causal influence on aggregate output and its growth. In contrast, our analysis suggests that such a nexus does exist if one disaggregates down to the sectorial level. We have distinguished three sectors in our analysis: industry, transport, and commercial \& consumer services. The rise of the "service economy" is characterized by a growth to dominance of the c\&c service sector in terms of value added and employment shares.

The reason for the phenomenon is, we have argued, that "cheap energy", i.e. a decreasing energy price/wage ratio, affects the sectors of the economy differently. Energy plays a much greater quantitative role in the production technologies of the industrial sector and in transport than in the service sector. The former sectors can

Table 3 Results of the ARDL Bounds Test (Dependent Variable: Labor Productivity)

\begin{tabular}{lllll}
\hline F-test & Macro & Industry & Commercial & Transport \\
\hline$\forall \beta=0$ & 4.25 & $5.65^{* *}$ & 4.19 & $5.95^{* *}$ \\
Const. & -0.3535 & -0.3776 & $5.1328^{* * *}$ & $-3.1920^{* *}$ \\
Adj. $R^{2}$ & 0.63 & 0.37 & 0.41 & 0.72 \\
Obs. & 34 & 32 & 34 & 32 \\
\hline
\end{tabular}

$* * *, * *, *$ denotes $1 \%, 5 \%, 10 \%$ level of significance, respectively 
therefore to a much larger extent take advantage of the changing relative input prices by substituting energy for labor (in tandem with the necessary capital that mediates energy use). The result is an increasing energy/labor ratio that, we have claimed, contributes to the productivity growth in industry and transport, but not in the service sector.

To provide empirical support for our hypothesis we have chosen data for the U.S. economy over the years 1970-2005, a particularly well suited period in the rise of the service economy in the U.S. In accord with the hypothesis it has been shown that productivity increases have in real, sectorial terms been significantly higher in industry and transport - the sectors with a high energy-output ratio - than in the c\&c service sector with its low energy intensity. The divergence that occurred between the sectors' labor productivity induced not only a migration of employment from industry to the commercial service sector. It also generated the lasting cost differentials epitomized by the cost disease which Baumol (1967) diagnosed for the service sector. The differentials have largely been compensated by a price level that rose faster for commercial services than for industrial products and transport services. When using a uniform macro deflator, productivity differences between the sectors are offset and, by the same token, the value added share of commercial services is blown up.

To provide statistical evidence for the hypothesis that the sectors' differing energetic conditions contributed to the productivity differentials we conducted a cointegration test on the basis of the U.S. data. That is, we analyzed the existence of a cointegration relationship between labor productivity and the variables derived from our model, particularly the energy-labor ratio, by means of the Autoregressive Distributed Lags (ARDL) bounds test. In support of the hypothesis we found evidence of cointegration in the sectors industry and transport, but not in the c\&c service sector. We have briefly outlined some policy conclusion that may be drawn from these findings.

Due to lack of data our analysis has not been able to account for other factors that may be driving sectorial change. For example, the offshoring of manufacturing activities to low-wage and/or less regulating countries and the corresponding substitution of imported for domestically manufactured products can be conjectured to also contribute to a rising value added and employment share of the domestic service sector of the highly developed economies. It has to be left to future research to assess and compare the influence of these changes of the international division of labor. Furthermore, our analysis covered a time period in which the digital revolution and internet-related transformations have not yet fully affected the production processes in the economy. However, these more recent technological developments are likely to have an impact on the structural change in the economy. In future research it will have to be explored, therefore, to what extent and in what way these new technologies are relevant for the energetic approach to the evolution of the service economy pursued here.

Acknowledgements We should like to thank the guest editor and two anonymous reviewers of this journal for their most helpful comments on an earlier draft of this paper. The usual disclaimer applies.

Funding Information Open access funding provided by Max Planck Society.

\section{Compliance with ethical standards}

Conflict of interest The authors declare that they have no conflict of interest. 
Open Access This article is distributed under the terms of the Creative Commons Attribution 4.0 International License (http://creativecommons.org/licenses/by/4.0/), which permits unrestricted use, distribution, and reproduction in any medium, provided you give appropriate credit to the original author(s) and the source, provide a link to the Creative Commons license, and indicate if changes were made.

\section{References}

Ayres RU, Simonis UE (1994) Industrial metabolism: theory and policy. In: Ayres RU, Simonis UE (eds) Industrial metabolism: restructuring for sustainable development. United Nations Press, New York, pp 320

Ayres RU, Warr B (2009) The economic growth engine - how energy and work drive material prosperity. Edward Elgar, Cheltenham

Baily MN, Bosworth BP (2014) US manufacturing: understanding its past and its potential future. J Econ Perspect 28(1):3-26

Baumol W (1967) Macroeconomics of unbalanced economic growth: the anatomy of the urban crisis. Am Econ Rev 57(3):415-426

Baumol W, Bowen W (1966) Performing arts: the economic dilemma. The Twentieth Century Fund, New York

Baumol WJ, Blackman SAB, Wolff EN (1985) Unbalanced growth revisited: asymptotic stagnancy and new evidence. Am Econ Rev 75(4):806-817

Berndt ER, Wood DO (1975) Technology, prices, and the derived demand for energy. Rev Econ Stat 57(3): $259-268$

Buenstorf G (2004) The economics of energy and the production process: an evolutionary approach. Edward Elgar Publishing, Cheltenham

Buera FJ, Kaboski JP (2012) The rise of the service economy. Am Econ Rev 102(6):2540-2569

Bureau of Economic Analysis (2010) Gross Domestic Product by Industry. United States Department of Commerce, http://www.bea.gov/industry/gdpbyinddata.htm

Bureau of Labor Statistics (2011). Labor force statistics from the current population survey. United States Department of Labor. http://data.bls.gov/timeseries/LNS14000000

Chenery HB (1960) Patterns of industrial Growth. Am Econ Rev 50(4):624-654

Costantini V, Paglialunga E (2014) Elasticity of substitution in capital-energy relationships: how central is a sector-based panel estimation approach. SEEDS working papers 1314, May 2014

Dechezlepretre A, Sato M (2017) The impacts of environmental regulations on competitiveness. Rev Environ Econ Policy 11(2):183-206

Energy Information Administration (2011a) Commercial sector energy consumption estimates, 1949-2010. United States Department of Energy. http://www.eia.gov/totalenergy/data/annual/showtext.cfm?t= ptb0201c

Energy Information Administration (2011b) Industrial sector energy consumption estimates, 1949-2010. United States Department of Energy. http://www.eia.gov/totalenergy/data/annual/showtext.cfm?t= ptb0201d

Energy Information Administration (2011c) Primary energy overview, 1949-2010. United States Department of Energy. http://www.eia.gov/totalenergy/data/annual/showtext.cfm?t=ptb0101

Energy Information Administration (2011d) Transportation sector energy consumption estimates, 1949-2010. United States Department of Energy. http://www.eia.gov/totalenergy/data/annual/showtext.cfm?t= ptb0201e

Engle RF, Granger CWJ (1987) Co-integration and error correction: representation, estimation, and testing. Econometrica 55(2):251-276

EU-KLEMS Growth and Productivity Accounts (2009a) Groningen growth and development centre. Basic Files. http://www.euklems.net

EU-KLEMS Growth and Productivity Accounts (2009b) Groningen growth and development centre. Capital Input Files. http://www.euklems.net

Federal Reserve Board (2011) Industrial production and capacity utilization. Federal Reserve Bank, Washington, DC. http://www.federalreserve.gov/releases/G17/default.htm

Fiorito G, van den Bergh JCJM (2016) Capital-energy substitution in manufacturing in seven OECD countries: learning about potential effects of climate policy and peak oil. Energy Efficiency 9(1):49-65 
Fixler DJ, Siegel D (1999) Outsourcing and productivity Growth in services. Struct Chang Econ Dyn 10:177194

Fourastié J (1952) Le Grand Espoir du XXe Siècle. Presses Universitaires de France, Paris

Georgescu-Roegen N (1971) The entropy law and the economic process. Harvard University Press, Cambridge

Gross C (2012) Explaining the (non-) causality between energy and economic growth in the U.S. - a multivariate sectorial analysis. Energy Econ 34(2):489-499

Henriques ST, Kander A (2010) The modest environmental relief resulting from the transition to a service economy. Ecol Econ 70(2):271-282

Houseman S, Kurz C, Lengermann P, Mandel B (2011) Off shoring Bias in U.S. manufacturing. J Econ Perspect 25(2):61-80

Johansen S, Juselius K (1990) Maximum likelihood estimation and inference on cointegration - with applications to the demand for money. Oxf Bull Econ Stat 52(2):169-210

Kellenberg DK (2009) An empirical investigation of the pollution haven effect with strategic environment and trade policy. J Int Econ 78(2):242-255

Kim J, Heo E (2013) Assymetric substitutability between energy and capital: evidence from the manufacturing sectors in 10 OECD countries. Energy Econ 40:81-89

Kuznets S (1971) Economic growth of nations - total output and production structure. Harvard University Press, Cambridge, MA

Narayan PK (2005) The saving and investment Nexus for China: evidence from cointegration tests. Appl Econ 37(17):1979-1990

Nordhaus WD (2008) Baumol's disease: a macroeconomic perspective. J Macroecon 8(1):1-37

Narayan PK, Smyth R (2007) Are Shocks to Energy Consumption Permanent or Remporary? Evidence from 182 Countries. Energy Policy 35 (1): 333-341.

Narayan PK, Smyth R (2008) Energy Consumption and Real GDP in G7 Countries: New Evidence from Panel Cointegration with Structural Breaks. Energy Economics 30 (5):2331-2341.

Pasinetti LL (1993) Structural economic dynamics. Cambridge University Press, Cambridge

Pesaran MH, Shin Y (1999) An autoregressive distributed lag modelling approach to cointegrated analysis. In: Strom S (ed) Econometrics and economic theory in the 20th century: the Ragnar Frisch centennial symposium. Cambridge University Press, Cambridge

Pesaran MH, Shin Y, Smith RJ (2001) Bounds testing approaches to the analysis of level relationships. J Appl Econ 16(3):289-326

Phillips PCB, Perron P (1988) Testing for a unit root in time series regression. Biometrika 75(2):335

Schettkat R (2007) The astonishing regularity of service employment expansion. Metroeconomica 58(3):413435

UNESCO Institute for Statistics (2011) School life expectancy. United Nations Educational, Scientific and Cultural Organisation, New York http://stats.uis.unesco.org/unesco/TableViewer/tableView. aspx?ReportId $=185$

Walker WR (2013) The transitional costs of sectorial reallocation: evidence from the clean air act and the workforce. Q J Econ 128(4):1787-1835

Publisher's note Springer Nature remains neutral with regard to jurisdictional claims in published maps and institutional affiliations. 